\title{
On the cumulant expansion up scaling of ground water contaminant transport equation with nonequilibrium sorption
}

\author{
Hakan Sirin · Miguel A. Mariño
}

Published online: 26 November 2008

(C) Springer-Verlag 2008

Erratum to: Stoch Environ Res Risk Assess (2008)

\section{2:551-565}

DOI 10.1007/s00477-007-0174-6

1. We apologize for the misspelling of the word "commutativity" as "commudativity" throughout the manuscript.

2. The sign of the second term in $(1,1)$ element of $\alpha A_{1}(t)$ on page 555, the third term in $(1,1)$ element of $\alpha A_{1}^{+}\left(x+\varsigma^{*}, \tau\right)$ on page 563 , and the second term in $(1,1)$ element of $\alpha A_{1}^{++}\left(x+\varsigma^{*}, \tau\right)$ on page 564 should be positive.

The online version of the original article can be found under doi:10.1007/s00477-007-0174-6.

H. Sirin $(\bowtie)$

Civil Engineering Department, Anadolu University,

26555 Eskisehir, Turkey

e-mail: hsirin@anadolu.edu.tr

M. A. Mariño

Hydrology Program and Department of Civil and Environmental Engineering, University of California, Davis, CA 95616, USA

e-mail: MAMarino@ucdavis.edu 